\title{
Explorando a matemática e a física com o robô seguidor de linha na perspectiva da robótica
}

\section{livre}

\author{
Exploring mathematics and physics with line follower robot from \\ the perspective of free robotics
}

\author{
Daniel da Silveira Guimarães (D) $* 1$, Élida Alves da Silva (D) ${ }^{\dagger 2}$ e \\ Fernando da Costa Barbosa (iD $\ddagger 1$ \\ ${ }^{1}$ Universidade Federal de Catalão, Catalão, GO, Brasil. \\ ${ }^{2}$ Universidade Federal de Goiás, Goiânia, GO, Brasil
}

\begin{abstract}
Resumo
Este trabalho propicia uma ferramenta para exploração de conteúdos matemáticos de maneira instigante. É um desafio para os professores da Educação Básica fomentar a participação ativa de estudantes na construção do próprio conhecimento. Neste contexto, a produção de instrumentos que facilitem a inovação em aulas de Matemática é relevante. A investigação, na qual se baseia este texto, foi desenvolvida a partir de uma pesquisa bibliográfica e da construção/experimentação de um robô seguidor de linha, na perspectiva do reaproveitamento de sucata e exploração da matemática subjacente. Como resultado, apresenta-se uma proposta de material didático de apoio, onde é tratada a construção de um seguidor de linha totalmente sustentável e são descritas possibilidades de abordagem de diversos conteúdos, evidenciando problemas que constituem desafios matemáticos e físicos. Outros pontos fortes da proposta são: possibilitar o acesso às contribuições dessa abordagem na educação pública e promover uma sensibilização a respeito da necessidade de preservação do meio ambiente, reutilizando materiais eletrônicos na produção de robôs e abordando o descarte correto dos materiais que não serão (re)aproveitados.
\end{abstract}

Palavras-chave: Robótica livre. Matemática. Seguidor de linha.

\section{Texto \\ Linguagem e Tecnologia \\ DOI: $10.35699 / 1983-$ \\ 3652.2021 .24895 \\ Seção: \\ Robótica pedagógica}

Autor Correspondente:

Fernando Barbosa

Editado por:

Leonardo Araújo

Recebido em:

23 de agosto de 2020

Aceito em:

22 de setembro de 2020

Publicado em:

3 de dezembro de 2020

Essa obra tem a licença "CC BY 4.0".

())

\begin{abstract}
This work provides a tool for exploring mathematical contents in an exciting way. It is a challenge for Basic Education teachers to foster the active participation of students in building their own knowledge. In this context, the production of instruments that facilitate innovation in mathematics classes is relevant. The investigation, on which this text is based, was developed from a bibliographic research and the construction/experimentation of a line follower robot, in the perspective of the reuse of scrap and exploration of the underlying mathematics. As a result, a proposal for didactic support material is presented, where the construction of a totally sustainable line follower is treated and possibilities for approaching different contents are described, showing problems which constitute mathematical and physical challenges. Other strengths of the proposal are: to enable access to the contributions of this approach in public education and to raise awareness of the need to preserve the environment, reusing electronic materials in the production of robots and the approach of correct disposal of materials that will not be (re)used.
\end{abstract}

Keywords: Free robotics. Mathematics. Line follower.

\section{Introdução}

Atualmente, os termos robô e robótica são palavras que fazem, cada vez mais, parte do contexto das pessoas. Contudo, muitas vezes, ao ouvir falar em robôs os indivíduos imaginam robôs humanoides ou de filmes de ficção científica. Entretanto, Pazos (2002, p. 8) define robô como uma máquina automática programável. Na concepção apresentada pelo autor, máquina é qualquer dispositivo capaz de transformar qualquer tipo de energia em trabalho útil, do ponto de vista físico. Define também que

\footnotetext{
*Email: danielguimaraes@ufg.br

†Email: elida_alves@ufg.br

‡Email: fcbarbosa@ufg.br
} 
ela será automática se sua "energia provém de uma fonte externa" (PAZOS, 2002, p. 7). Por fim, ele entende por programável uma máquina "cujo trabalho depende, em certa medida, de instruções previamente dadas pelo operador, seja qual for o meio pelo qual foram introduzidas essas instruções na máquina e o formato delas" (PAZOS, 2002, p. 7). Neste sentido, existem vários tipos de robôs com os quais o contato é frequente. Por exemplo, nos noticiários estão sendo divulgadas notícias sobre robôs que disparam fake news, os chatbots, os quais também são utilizados por instituições para atendimento via chat; ao telefonar para diversas empresas as pessoas podem ser atendidas por atendentes virtuais; nos lares podem ser utilizados aspiradores robôs; nas empresas, diferentes mecanismos estão em trabalho, os robôs industriais.

Neste trabalho será utilizado um seguidor de linha que é um robô. Essa designação se baseia nos seguintes fatos: ele transforma energia elétrica em força para o deslocamento do seguidor, é automático por utilizar energia de uma bateria e é programável por ter recebido instruções do operador, por meio da organização dos componentes eletrônicos que permitem a utilização dos dados obtidos por eles de forma pré-definida.

Neste contexto, a formação dos cidadãos, além de propiciar conhecimentos básicos, deve buscar a construção de habilidades e competências para o indivíduo adaptar-se à dinamicidade do mercado de trabalho. Portanto, é necessário instigar as pessoas a sempre se questionarem, "Como foi feito? Como funciona? Como posso construir? Como posso aperfeiçoar?", propiciando a elaboração de novas ideias. Constata-se um grande crescimento da oferta de cursos envolvendo programação, robótica e atividade maker (faça você mesmo), contudo esse deveria ser um dos objetivos das escolas. Segundo Santos (2019, p. 27) "a educação deve se incumbir da tarefa de se apropriar da agenda tecnológica do nosso tempo, da nossa época tecnológica, com suas particularidades e contradições".

Um caminho para o envolvimento da rede de ensino com a tecnologia é a robótica educacional (RE) ou robótica pedagógica. São, praticamente, quarenta anos de desenvolvimento desse tipo de robótica, mas só com a evolução das tecnologias e seu barateamento é que começou a ser difundida. Lopes (2008, p. 41) define a RE "como um conjunto de recursos que visa ao aprendizado científico e tecnológico integrado às demais áreas do conhecimento, utilizando-se de atividades como design, construção e programação de robôs".

"A Robótica Educacional proporciona ao indivíduo a aprendizagem através da prática, além de estimular o raciocínio lógico, a criatividade e outras várias habilidades relacionadas" (SILVA et al., 2016, p. 76) e tem sido direcionada a trabalhos com materiais proprietários. Entretanto, existe outro caminho que pode ser seguido quando não se dispõe de recursos financeiros, a Robótica Educacional Livre. Inserir uma RE com baixo custo em escolas públicas do país é oportunizar acesso à uma educação tecnológica para indivíduos que não usufruem dela nos moldes operantes no país.

A RE livre, defendida por Danilo Rodrigues César, se refere à utilização de qualquer recurso eletrônico que possa ser (re)aproveitado, oriundo de sucata ou não, e que seja flexível no processo de construção. Nesta linha de trabalho podem ser realizadas pesquisas e produção de materiais didáticos, como meio de difusão da Robótica no meio educacional do país. A diminuição do custo e a criação deste material de apoio aumenta o alcance das propostas, possibilitando a inserção de muitos alunos no universo da Robótica Educacional.

Neste contexto, tem origem a proposta deste artigo, a partir do qual pretende-se investigar "Como se desenvolve uma ação de robótica livre que explore conhecimentos científicos?" A partir deste questionamento inicial, surge uma pergunta mais específica tendo como centro um robô seguidor de linha, ou seja, "Quais adaptações podem ser feitas na proposta de construção de um seguidor de linha, para se trabalhar na perspectiva livre, mantendo a eficiência e a eficácia, e estabelecer uma sequência didática (SD) envolvendo conteúdos de Matemática e Física neste processo?". O público alvo é formado por professores de Matemática e Física que gostariam de trabalhar com RE e o objetivo é que este trabalho sirva como material didático de apoio. Nele é abordada a construção de um seguidor de linha sustentável, possibilitando garantir o acesso às contribuições dessa abordagem na educação pública. São descritas possibilidades de abordagem de diversos conteúdos, os quais constituem desafios matemáticos e físicos. Alguns destes problemas podem ser resolvidos por meio de testes, contudo a otimização do tempo gasto e a construção de conhecimentos científicos, devem 
ser valorizados pelos professores.

Ressalta-se outro ponto forte da proposta, a sensibilização a respeito da necessidade de preservação do meio ambiente, a partir do desafio de reutilizar materiais eletrônicos na produção de robôs e a abordagem do descarte correto dos materiais que não serão (re)aproveitados.

Inicialmente, será abordado o tema Robótica Educacional, buscando embasamento teórico em trabalhos de outros pesquisadores. Na Seção 3, será explicitada a proposta de montagem do robô seguidor de linha idealizado pelos autores, bem como o relato do desenvolvimento da pesquisa. Nas Seções 4 e 5, serão elencadas possibilidades para se trabalhar a Matemática e Física subjacente, considerando que seria o primeiro trabalho nesta perspectiva, aplicado pelo professor interessado. A Seção 6 tem por objetivo motivar novas experiências por parte dos leitores, abordando a possibilidade de substituição de componentes. Por fim serão apresentadas as considerações finais.

\section{Sobre a robótica educacional e a proposta do trabalho}

Em 1980, Seymour Papert já dizia que utilizar a tecnologia em prol do desenvolvimento do pensamento humano, é buscar "um fim à cultura que faz com que a ciência e a tecnologia sejam estranhas para a grande maioria das pessoas" (PAPERT; FREIRE, 1980, p. 4, tradução nossa). Existem diversas maneiras de utilizar as tecnologias na educação, em prol do desenvolvimento humano. Neste trabalho será abordada a Robótica Educacional (RE), na perspectiva livre, por meio da qual busca-se a apropriação de materiais eletrônicos descartados no lixo e criatividade para sua reutilização. Mill e Cesar definem robótica livre como

o conjunto de processos e procedimentos envolvidos em propostas de ensino-aprendizagem que tomam os dispositivos robóticos baseados em soluções livres e em sucatas como tecnologia de mediação para a construção do conhecimento (MILL; CÉSAR, 2009, p. 222).

Segundo Barbosa (2016, p. 71), a robótica pode ser "construída em diferentes contextos, espaços, com diferentes agentes e podendo ou não usufruir de uma metodologia". Além disso, Campos (2005, p. 60) ressalta que o indivíduo ao saber "os 'como' e 'porquês' por detrás de um conceito, ele não somente terá um melhor entendimento das informações, mas terá a habilidade de aplicar os conceitos em qualquer outro lugar". O importante, como dizia Barbosa (2016, p. 44). é saber usar dos recursos disponíveis de modo a transformar o mundo, criar, ser autor nesse processo. Aprender com o objeto.

Ademais, em um mundo onde o discurso de sustentabilidade é composto por palavras de efeito, o exercício da robótica livre é uma oportunidade de contribuir para a preservação do meio ambiente, bem como para a formação humana, que precisa transcender o conhecimento científico. Como Mill e Cesar (2009, p. 219) reforçaram, existe a possibilidade de explorar com a robótica questões éticas, morais, culturais, socioeconômicas e humanas. Outro ponto forte dessa abordagem é propiciar um menor custo para realização das ações, como os autores mencionaram

O uso de soluções livres e de componentes de equipamentos eletromecânicos e eletrônicos fora de uso (sucata) garante a possibilidade de manipulação em um nível mais estrutural e uma diminuição drástica nos custos do projeto (MILL; CÉSAR, 2009, p. 227).

Ao analisar a infraestrutura de algumas instituições de educação pública, percebe-se que um dos desafios para a inserção das aulas de tecnologia e robótica é a falta de equipamentos essenciais como computador com internet, kits de robótica, entre outros. Além disso, conforme Ben e Santos (2019, p. 175) afirmaram

a falta de habilidades e competências técnicas para o uso das tecnologias, a resistência à aquisição de uma nova postura por parte dos professores, o tempo dispendido para elaboração de material instrucional[...] e a falta de um suporte efetivo das instituições aos professores são alguns dos entraves que ainda permanecem no universo escolar.

A partir dessa constatação manifesta-se, nos profissionais para os quais é importante o desenvolvimento de atividades dessa área, as seguintes inquietações: como tornar esse conhecimento acessível 
a jovens de uma escola pública sem recursos? Como promover uma educação tecnológica inclusiva? Um caminho que pode abrandar essa inquietação é a RE livre. Além de ser mais acessível do ponto de vista econômico, essa robótica sustentável atende os preceitos estabelecidos pela BNCC, buscando

exercitar a curiosidade intelectual e recorrer à abordagem própria das ciências, incluindo a investigação, a reflexão, a análise crítica, a imaginação e a criatividade, para investigar causas, elaborar e testar hipóteses, formular e resolver problemas e criar soluções (inclusive tecnológicas) com base nos conhecimentos das diferentes áreas (BRASIL, 2018, p. 9).

Mesmo na RE livre ainda são presentes alguns entraves, por exemplo como fazer robótica se não há computadores? Como e onde encontrar peças? Contudo, cada problema a ser superado, expande o grau de evolução do processo de ensino e aprendizagem, pois a busca por soluções propicia a construção de conhecimentos diversos para os envolvidos. Ademais, tornar a reflexão sobre esse tipo de problema parte do cotidiano das turmas que participam das ações é fundamental para despertar, além de ideologias políticas que embasarão a luta por mais investimentos na educação, a curiosidade e a criatividade de como fazer algo novo do que já não é utilizado e será descartado no lixo.

Uma equipe de professores de uma universidade pública de Goiás, ao lidar com essas inquietações e fazer pesquisas em eletrônica, se deparou com a construção de seguidores de linha, também conhecido como AGV (Automated Guided Vehicle). Há alguns vídeos no YouTube apresentando mecanismos com essas características, por exemplo "Como fazer um robô que dirige sozinho" (2017). Porém, essa equipe planejou adaptações para utilização de sucatas. Além disso, durante o desenvolvimento da proposta, foi considerado como eixo norteador o enfoque/estudo da Matemática subjacente.

Esse seguidor de linha, construído para seguir uma trajetória específica que, no caso em tela, é uma trajetória demarcada por uma fita isolante preta em uma base clara, não pressupõe o uso de computadores. Sua programação está relacionada à construção do hardware, potencializando ainda mais o alcance das atividades planejadas. Assim, pensando em fomentar a inclusão digital de estudantes de escolas públicas e atender à nova BNCC, propõe-se nesse trabalho, a montagem de um seguidor de linha a custo zero, a partir da reutilização de circuitos eletrônicos.

\section{Sobre a construção do AGV}

A montagem do robô se inicia com o recolhimento de componentes de equipamentos eletrônicos descartados (sucata), seguida da montagem da estrutura, finalizando com a construção da parte eletrônica.

Para procurar os materiais, é importante a utilização de equipamentos de segurança e pesquisar sobre o correto manuseio da sucata eletrônica, de modo a não sofrer acidentes e não danificar os componentes. Recomenda-se o acompanhamento de vídeos instrutivos disponíveis na internet que abordam estes temas. Os materiais necessários e as possíveis sucatas de onde alguns deles podem ser retirados/reutilizados estão listados na Tabela 1 .

Tabela 1. Componentes e ferramentas.

\begin{tabular}{|c|c|c|c|}
\hline Finalidade & Material & Qtd & Fonte \\
\hline & Chassi & 1 & $\mathrm{ACM}^{1}$, capa rígida de caderno \\
\hline \multirow[t]{4}{*}{ Estrutura } & Roda dianteira & 1 & Roll-on labial ou de desodorante roll-on \\
\hline & Roda traseira & $2^{2}$ & Chinelo \\
\hline & Placa (fixar componentes) & 1 & placa ou pasta de plástico \\
\hline & $\begin{array}{l}\text { Resistor } 300 \Omega \text { (ou } 1 \text { de } 220 \Omega \text { e } 1 \text { de } \\
100 \Omega \text { colocados em série) }\end{array}$ & 2 & Placas de TV de tubo ou de som \\
\hline $\begin{array}{l}\text { Circuitos } \\
\text { Eletrônicos }\end{array}$ & $\begin{array}{l}\text { LED (Light Emitting Diode) alto } \\
\text { brilho }\end{array}$ & $2^{2}$ & Mouse ou luminária de emergência \\
\hline
\end{tabular}


Transistor

LDR (Light Dependent Resistor)
$5 \mathrm{~mm}$

Motores e engrenagens

Potenciômetro $500 \Omega$ a $10 \mathrm{~K} \Omega$

Chave (liga/desliga)

Clip conector de bateria 9V

Fios reutilizados
TV de tubo Philips (BD 136 (PNP); BD135 (NPN)) amplificador de som analógicos de carro ou comercial (BD140, TIP's 105 e 107 (PNP); BD 139,TIP's 102, 120 e 122 (NPN))

2 Câmara de segurança ou relé fotoelétrico

$2^{3} \quad$ Aparelho de DVD ou leitora de DVD de computadores ou de som doméstico

$4^{4} \quad$ Placas de TV de tubo e som

1 Brinquedos, aparelhos eletrônicos ou TV de tubo

1 Bateria velha ou brinquedos

\begin{tabular}{ll} 
Furadeira & 1 \\
Chave phillips & 1 \\
Broca (1mm, 1.5mm,2.5mm, & 4 \\
$3.5 \mathrm{~mm})$ & \\
Parafuso com porca (fixar as rodas & 1 \\
para lixar) & \\
Ferro de solda & 1 \\
Multímetro (opcional) & 1 \\
Estanho & 1 \\
Lâmina para arco de serra & 1 \\
Ferramentas & 1 \\
Pistola de cola quente & 1 \\
Cola quente & 1 \\
Tesoura ou estilete & 1 \\
Compasso & 1 \\
Régua & 1 \\
Supercola & 1 \\
Fita isolante & 1 \\
Cartolina chambril (pista) & 2 \\
Lixa & 1 \\
Prego & \\
Canudo & \\
Luvas isolantes & \\
& \\
Óculos de proteção & \\
\hline
\end{tabular}

Fonte: Acervo dos autores.

Após retirar os componentes necessários e aqueles que podem ser armazenados para outros projetos, é importante o descarte correto dos materiais não utilizados, procurando por cooperativas/empresas de reciclagem ou outros postos de coleta disponíveis na cidade. Inicia-se então a segunda etapa, montagem da estrutura do AGV.

\subsection{Construção da estrutura do AGV}

O objetivo do AGV é percorrer uma trajetória, construída com linha preta em uma superfície clara, com velocidade e tempo gasto otimizados. Serão descritas duas experiências de montagem, cujos materiais podem ser substituídos por equivalentes que constam ou não na Tabela 1. As medidas também podem

3 Podem ser diferentes, desde que os motores tenham tensões próximas e engrenagens como mesmo número de dentes.

4 Dois pares iguais. Podem ser substituídos por resistores após testes, pois os potenciômetros são reguláveis. 
ser alteradas. Entretanto, para efetivar as alterações é necessário fazer análises matemáticas que serão discutidas em outro momento. O objetivo do artigo supracitado é possibilitar a troca de componentes, mantendo a eficiência e eficácia do robô, propiciando maior leque de componentes:

1. O primeiro item a ser confeccionado é o chassi, suporte para os componentes.

1.1 Em um ACM desenhe a Figura 1, onde triângulo de referência é isósceles, cujo centro de massa foi encontrado.

1.2 Recorte o chassi.

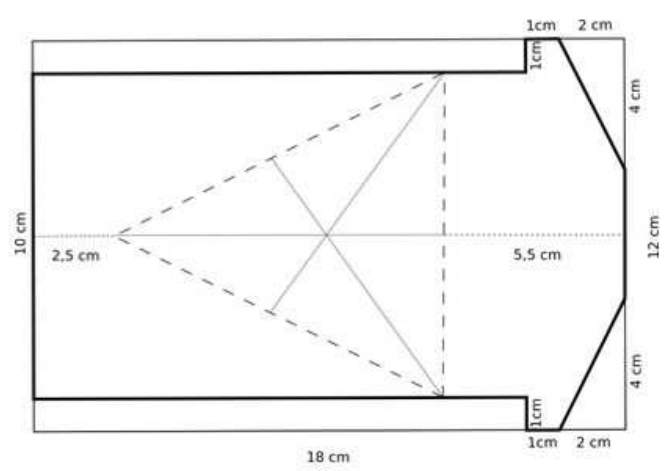

(a)

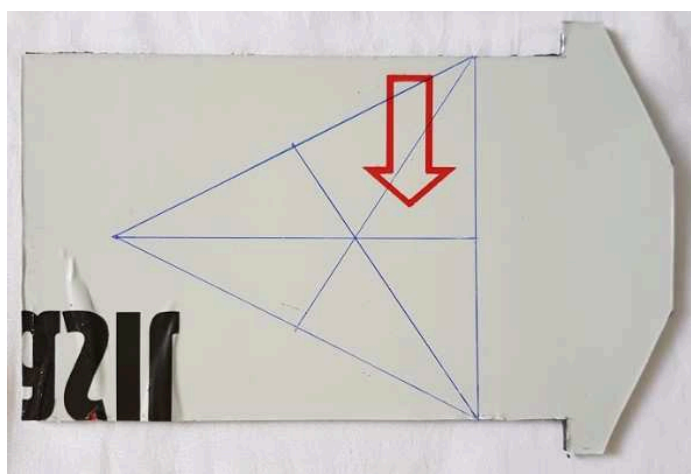

(b)

Figura 1. Chassi.

Fonte: Acervo dos autores.

2. Quanto aos motores, retire dois conjuntos de engrenagens, polias e motores presentes em leitoras de DVD de computadores.

2.1 Com uma lâmina para arco de serra, retire os componentes como indicado na Figura 2.

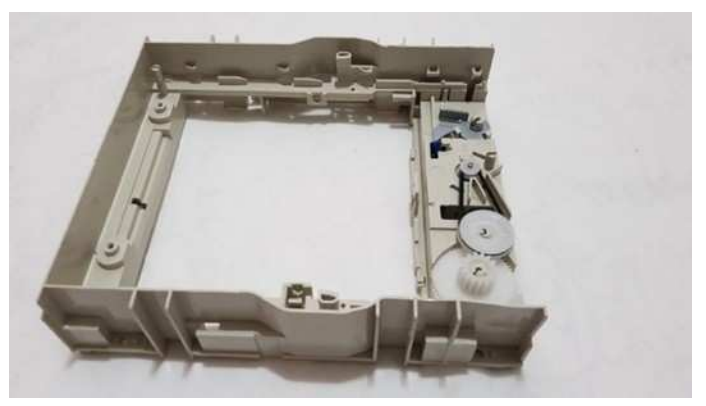

(a)

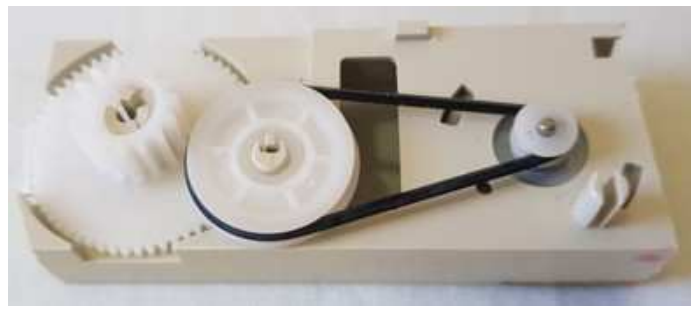

(b)

Figura 2. Engrenagens e motores.

Fonte: Acervo dos autores.

2.2 Desenhe dois círculos de raio $2,5 \mathrm{~cm}$ em um chinelo. Recorte-os para confeccionar as rodas traseiras. Prenda cada círculo em um parafuso com rosca, fixe-o na furadeira e, a partir de autorrotação, faça o acabamento com uma lixa. Com prego, faça sulcos nas rodas para garantir maior atrito. Fixe essas rodas com supercola nas engrenagens, conforme Figura 3. Caso for necessário, as rodas podem ser fixadas com uma estrutura de eixo, utilizando rebites e conectores de chuveiros. 


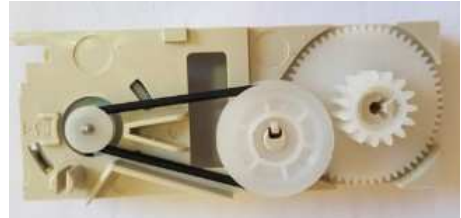

(a)

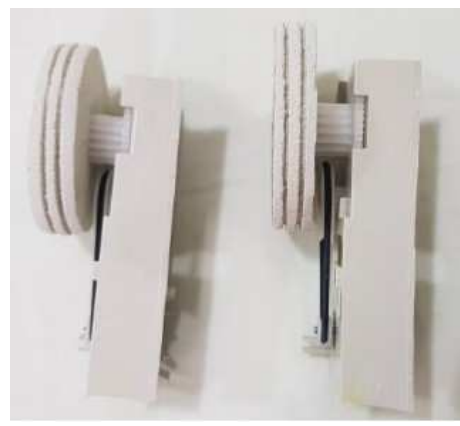

(b)

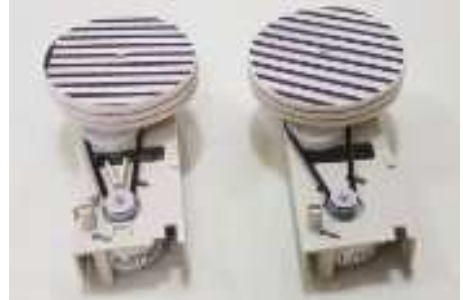

(c)

Figura 3. Fixação das rodas.

Fonte: Acervo dos autores.

2.3 Fixe as duas estruturas de motor/polias/engrenagens/rodas no chassi com supercola ou parafusos e porcas. Cada uma delas deve ser fixada próxima à uma das bordas do chassi, de forma que o eixo da roda esteja alinhado ao vértice da base do triângulo referência, conforme Figura 4.

3. Corte o vidro do roll-on labial deixando a esfera presa à base cilíndrica, para usá-lo como roda dianteira. A altura total deve ser aproximadamente $4 \mathrm{~cm}$ (a altura da frente do AGV deve ser compatível com a da traseira). Fixe a roda no chassi, com o centro alinhado ao vértice superior do triângulo referência, conforme Figura 4.

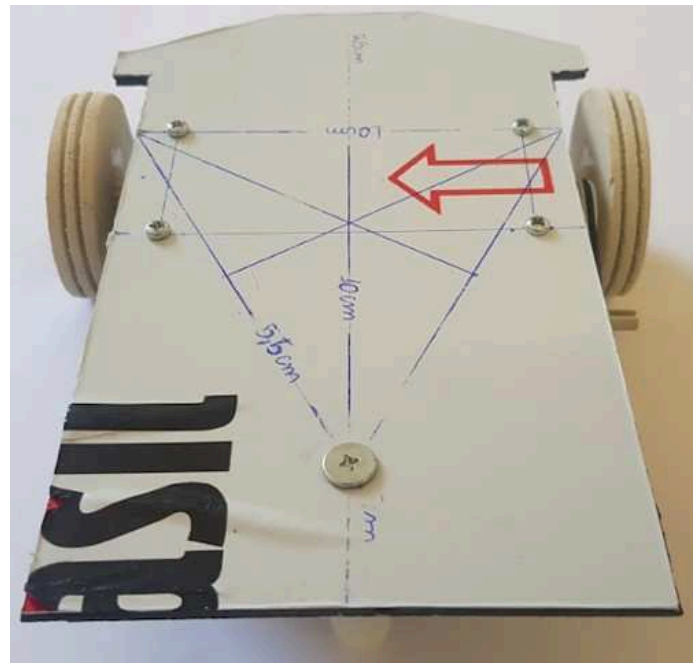

(a)

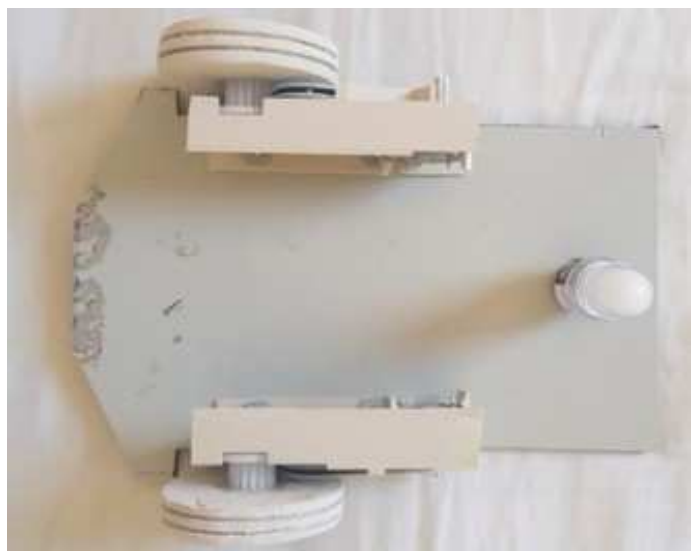

(b)

Figura 4. Estrutura do AGV.

Fonte: Acervo dos autores.

Construída a parte estrutural, segue-se para parte eletrônica do robô.

\subsection{Construção da parte eletrônica do AGV}

O circuito eletrônico ${ }^{5}$ do AGV, para cada roda, será separado em três partes, a saber LED-resistor, LDR-potenciômetro e motor-potenciômetro-transistor. Ressalta-se que a fonte de alimentação e a chave liga/desliga são compartilhadas pelas três partes. Será feita uma breve descrição dos circuitos, os quais serão detalhados na sequência.

O circuito LED-resistor tem como objetivo iluminar a trajetória do robô, propiciando uma leitura adequada do LDR. Enquanto o LED possui a atribuição iluminar, o resistor evita que o LED se queime, promovendo resistência à corrente e, por conseguinte, à tensão elétrica.

5 Todo circuito pode também ser simulado em uma protoboard ou nos softwares Tinkercad ou Proteus 8. 
O circuito LDR-potenciômetro trabalha com o objetivo de manter o veículo na trajetória. No momento em que um LDR focaliza a linha preta, a tensão do respectivo circuito diminui, liberando uma quantidade menor corrente e tensão para o transistor e, consequentemente, para o motor correspondente. Assim, causa a baixa de velocidade do motor e a correção da trajetória.

O circuito motor-potenciômetro-transistor é o responsável por promover a locomoção do robô. O transistor regula a quantidade de tensão no motor. O potenciômetro permite correções nas altas tensões que passariam para o motor, evitando velocidades muito altas e imprecisão do AGV. A velocidade de rotação do motor depende da tensão nele.

\subsubsection{Primeiro circuito do AGV: LED-resistor}

O LED é um diodo que converte energia elétrica em luz. Só permite que a corrente flua em uma direção, do lado positivo - ânodo - para o lado negativo - cátodo (atenção ao design interno das colunas do LED na Figura 5b). Nesta pesquisa foram utilizados os LED retratados da Figura 5a.
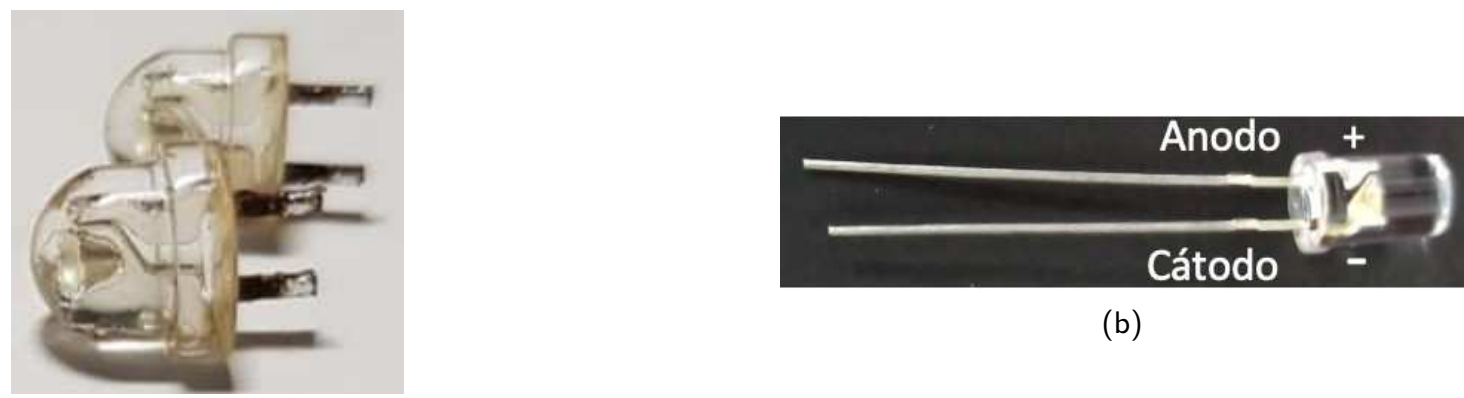

(b)

(a)

Figura 5. LED.

Fonte: Acervo dos autores.

O resistor, Figura 6, é um componente que oferece uma oposição à passagem de corrente elétrica através de seu material. Essa oposição é denominada resistência elétrica. O resistor não possui polaridade, ou seja, não tem lados positivo e negativo.

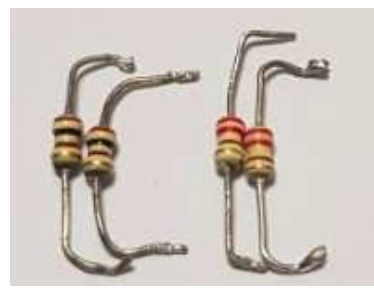

Figura 6. Resistores.

Fonte: Acervo dos autores.

O primeiro circuito é composto por (a) fonte de alimentação com tensão $V_{F A}=9 \mathrm{~V}$ (bateria de 9V), (b) chave liga/desliga, (c) resistor e (d) LED, conforme Figura 7.

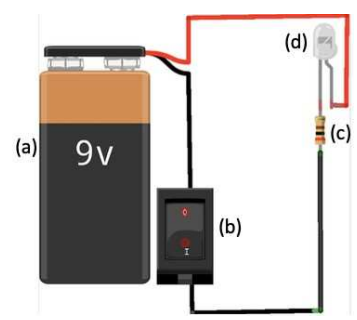

Figura 7. Primeiro Circuito.

Fonte: Acervo dos autores.

Os LED são de $3 \mathrm{~V}$ e corrente máxima de $20 \mathrm{~mA}=0,02 \mathrm{~A}$. O valor nominal do resistor, que será 
calculado na Seção 5.3, deve ser $300 \Omega$, o qual pode ser substituído por um resistor de $220 \Omega$ e um de $100 \Omega$ colocados em série.

\subsubsection{Segundo circuito do AGV: LDR-potenciômetro}

Potenciômetro, Figura 8, é um componente que possui resistência elétrica ajustável. Geralmente, é um resistor de três terminais, onde a conexão central é deslizante e manipulável. Serão utilizados potenciômetros lineares (sufixo B ao final do código).

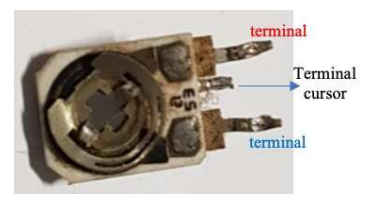

Figura 8. Potenciômetro.

Fonte: Acervo dos autores.

LDR, Figura 9, é um resistor cuja resistência varia conforme a intensidade da luz que incide sobre ele, o qual não possui polaridade nos terminais. Quanto maior a intensidade da luz mais a resistência diminui. Optou-se por utilizar um LDR de $5 \mathrm{~mm}$.

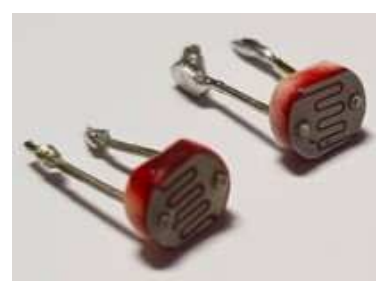

Figura 9. LDR.

Fonte: Acervo dos autores.

O segundo circuito é composto pela (a) fonte de alimentação, (b) chave liga/desliga, (e) potenciômetro e (f) LDR, conforme Figura 10.

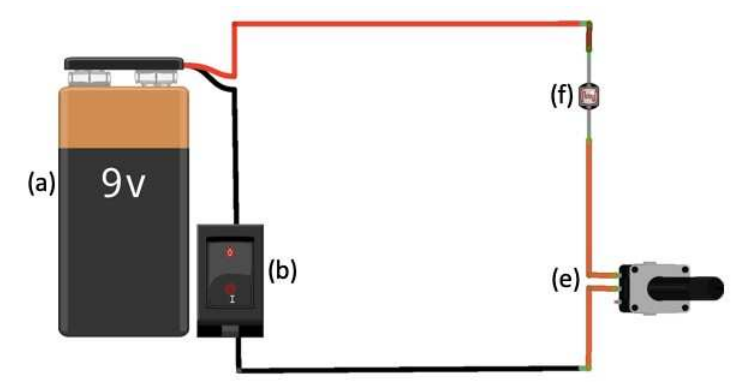

Figura 10. Segundo Circuito.

Fonte: Acervo dos autores.

Os potenciômetros desse circuito devem ser ajustados de acordo com os transistores (Seção 3.2.3) utilizados no AGV, conforme as seguintes faixas 
Tabela 2. Faixa de variação do potenciômetro ou resistor.

\begin{tabular}{lll}
\hline Transistor & Potenciômetro ou resistor \\
\hline NPN & PNP & $\begin{array}{l}\text { Faixa de variação para funcionamento do } \\
\text { circuito }\end{array}$ \\
\hline TIP's 102, 120 e 122 & TIP's 105 e 107 & $200 \Omega$ à $600 \Omega$ \\
\hline & BD's 140 e 136 & $120 \Omega$ à 330 $\Omega$ \\
\hline BD's 135 e 139 & & \\
\hline
\end{tabular}

Fonte: Acervo dos autores.

\subsubsection{Terceiro circuito do AGV: motor-potenciômetro-transistor}

$\mathrm{O}$ terceiro circuito é o programador do AGV. Existem vários tipos de transistores, o que propicia o desafio de descobrir as alterações necessárias no circuito para cada modelo. Serão tratados neste artigo somente transistores NPN e PNP, nos modelos BD e TIP.

O transistor, Figura 11, é um dispositivo semicondutor usado para amplificar ou oscilar sinais eletrônicos e potência elétrica. Também pode ser usado como chave eletrônica. É composto por três terminais, base, coletor e emissor. A informação de qual terminal é base, coletor ou emissor deve ser verificada no datasheet do componente.

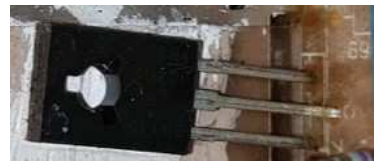

Figura 11. Transistor.

Fonte: Acervo dos autores.

É possível comparar o funcionamento do transistor a uma torneira de água, na qual a regulação da quantidade de água que sai, depende do quanto se abre a válvula. No caso do transistor, será regulada, pela base, a quantidade de corrente elétrica. Na Figura 12, pode-se visualizar em esquema as diferenças dos transistores NPN e PNP.
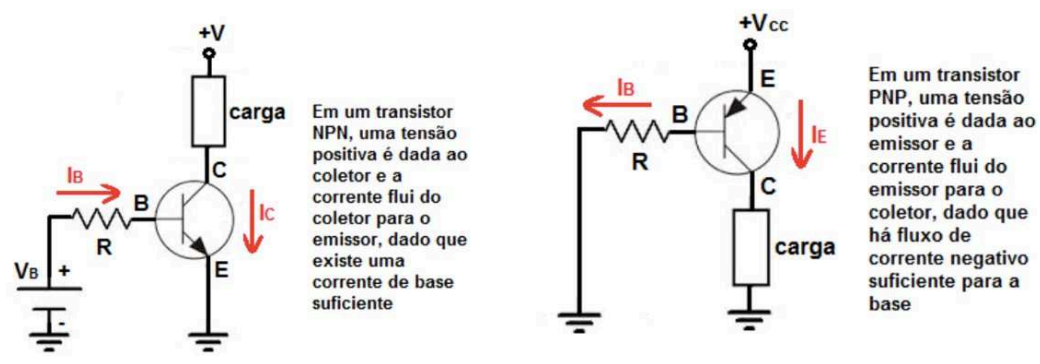

Figura 12. Esquema de transistores NPN e PNP.

Fonte: Aprender sobre eletrônicos http://www.learningaboutelectronics.com/Artigos/Diferenca-entre-trans istores-NPN-e-PNP.php.

Um motor DC (direct current) é um motor elétrico rotativo que converte energia elétrica de corrente contínua em energia mecânica. A velocidade de um motor DC pode ser controlada em uma ampla faixa, usando uma tensão de alimentação variável ou alterando a força da corrente em seus enrolamentos de campo. Esses motores revertem a rotação quando se troca a polarização. Foi utilizado um motor que sai do repouso com uma tensão maior que $2,8 \mathrm{~V}$, conforme informação do datasheet ${ }^{6}$.

6 Disponível em: https://datasheetspdf.com/parts/RF-300EA-1D390. pdf?id=917203. 
O conjunto de motores/polias/engrenagens não precisam ser idênticos, porém é necessário que os motores tenham tensões próximas e as engrenagens devem ter o mesmo número de dentes.

O terceiro circuito é composto por (a) fonte de alimentação, (b) chave liga/desliga, (g) motor DC (h) potenciômetro e (i) transistor. Na Figura 13 estão esquematizados os três circuitos integrados, com (a) fonte de alimentação, (b) chave liga/desliga, (c) resistor, (d) LED, (e) potenciômetro, (f) LDR, (g) motor DC, (h) potenciômetro e (i) transistor. Para este esquema foi considerado um transistor NPN BD. Para trabalhar com um transistor PNP deve-se inverter a polarização do circuito, o que pode inferir da Figura 13 (cuidado com a polarização do LED em caso de inversão).

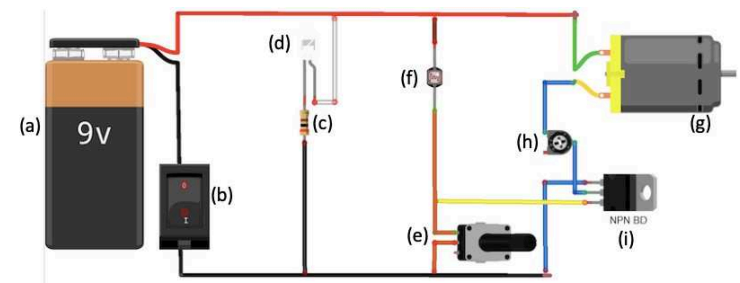

Figura 13. Terceiro Circuito.

Fonte: Acervo dos autores.

Entre segundo e o terceiro circuitos há uma leitura de corrente, essa leitura realizada pela base do transistor que irá controlar o AGV. Assim, um fio entre o LDR e potenciômetro é ligado à base do transistor, regulando-o eletronicamente.

Para fixação dos componentes eletrônicos no robô, inicia-se pelo LDR que deve ser colocado a uma altura de $1 \mathrm{~cm}$ do chão, dentro de um canudinho coberto com fita isolante preta. A iluminação, feita por um LED de alto brilho, também deve ser colocada a uma altura de $1 \mathrm{~cm}$ do chão e $1 \mathrm{~cm}$ de distância do LDR. Esses componentes podem ser acoplados ao chassi com supercola na parte inferior do robô, conforme indicado na Figura 14. Esta configuração foi utilizada para que o AGV possa seguir uma trajetória formada por fita isolante dupla de cor preta $(3,5 \mathrm{~cm}$ de largura) em uma base clara.

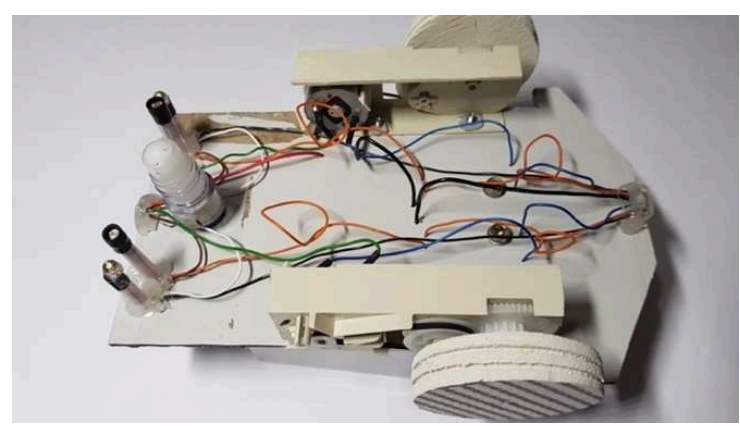

Figura 14. Parte inferior do AGV.

Fonte: Acervo dos autores.

$\mathrm{Na}$ parte superior, estabiliza-se a bateria no chassi, colocando-a em uma posição que propicie estabilidade ao robô. O ideal é usar como referência o centro de massa do triângulo, conforme Figura 1. Fixe a chave liga/desliga, os transistores e potenciômetros em uma placa de plástico rígido e depois cole a placa no chassi, conforme Figura 15. 


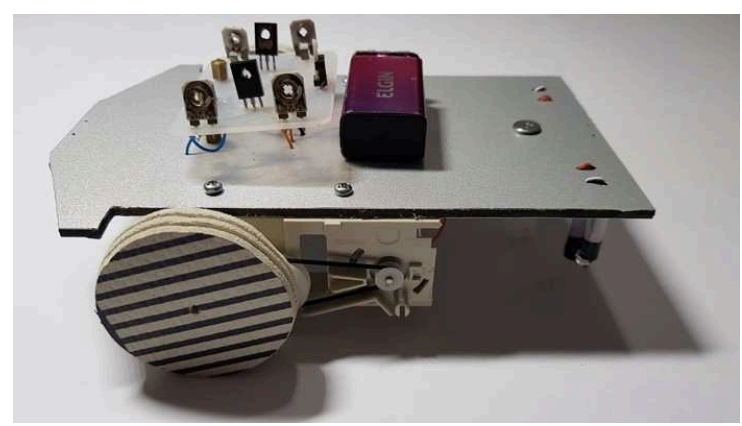

Figura 15. Parte superior do AGV.

Fonte: Acervo dos autores.

Segue na Figura 16 um esquema para orientar a montagem do circuito no AGV, com indicação dos furos para passagem dos fios. Todos os fios devem ser soldados aos componentes eletrônicos.

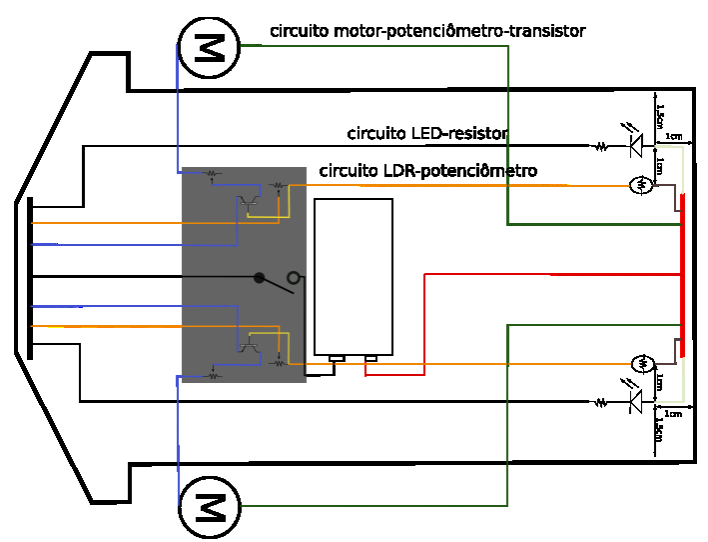

(a)

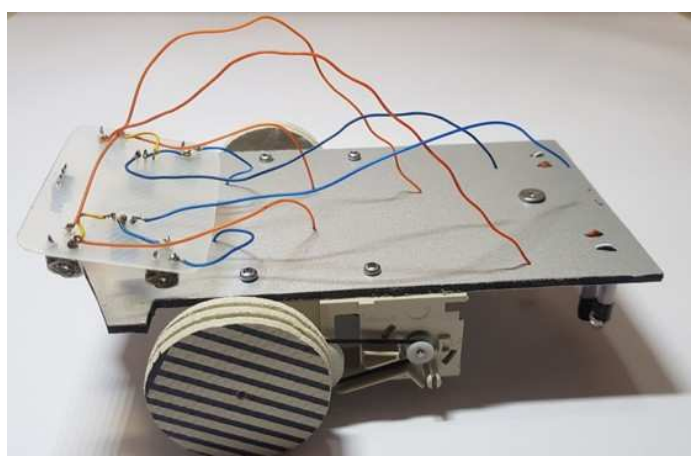

(b)

Figura 16. Circuitos no AGV.

Fonte: Acervo dos autores.

A construção do AGV está concluída e o processo de desenvolvimento da pesquisa será relatado a seguir.

\subsection{O Desenvolvimento da Pesquisa}

Inicialmente, foi construído um robô seguidor de linha utilizando as peças relacionadas em THENÓRIO (2020). O valor gasto para a aquisição delas foi $R \$ 113,40$. Posteriormente, iniciou-se a busca por respostas para o seguinte questionamento "Quais adaptações podem ser feitas na proposta de construção de um seguidor de linha, para se trabalhar na perspectiva livre, mantendo a eficiência e a eficácia, e estabelecer uma SD envolvendo conteúdos de Matemática e Física neste processo?". Esta investigação foi conduzida baseada na experimentação de componentes de sucatas que pudessem substituir as peças compradas, bem como na exploração da Matemática e Física subjacente. Neste processo, foram encontrados os componentes citados na quarta coluna da Tabela 1. Alguns problemas ocorreram neste processo e foram feitas adaptações para obter melhores resultados na performance do robô.

Nos experimentos executados, para o chassi foram utilizados 3 materiais distintos, pasta de plástico, capa rígida de caderno e ACM. O plástico, por ser muito flexível, não produziu o efeito desejado, os outros dois materiais foram boas opções. Além disso, nesta etapa foram pensados os conteúdos que possivelmente seriam abordados, de onde surgiu a necessidade de montar a Figura 1 para execução da SD.

Quanto aos motores, foram testados motores DC (de impressora) que eram velozes, porém não possuíam força suficiente para movimentar o robô. Portanto, foi necessária a utilização de conjuntos de engrenagens/polias/motores presentes em leitoras de DVD de computadores, o que propiciou um 
movimento mais preciso do robô. Esta alteração possibilitou a exploração de diversos conteúdos de Matemática e Física na SD.

A montagem da parte eletrônica foi feita, inicialmente, sem separações. A partir das experimentações, concluiu-se que a divisão em 3 partes facilitaria o entendimento, bem como a elaboração da SD. Foi elaborado um esquema, Figura 16, para montagem das partes do circuito. No segundo circuito foram testados tanto potenciômetros quanto resistores para estabelecer uma resistência elétrica. Apesar de serem opções funcionais, a descrição do circuito foi feita com base no potenciômetro. 0 terceiro circuito era composto por motor-transistor. Foram testados e validados diversos tipos de transistores NPN e PNP, os quais estão elencados na Tabela 2, a fim de facilitar a procura do componente em sucatas. Foram utilizados motores de $5.9 \mathrm{~V}$, por serem mais fáceis de serem encontrados em sucatas. Após os testes, optou-se pela inserção de potenciômetros entre os transistores e motores para proporcionar maior precisão ao movimento do robô. Contudo, se os motores forem substituídos por outros com tensão menor ou igual a 3V (menos comuns), é possível reduzir a tensão da fonte de alimentação para quatro pilhas, $4.8 \mathrm{~V}$, e o potenciômetro torna-se dispensável. A montagem da parte eletrônica do robô também foi trabalhada na SD.

Sobre a escolha do resistor no circuito LED-resistor, na primeira versão, foi utilizado um resistor

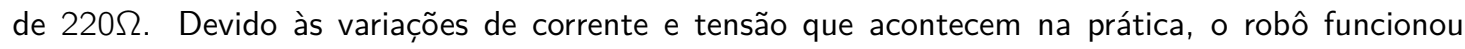
sem problemas. Contudo, ao trabalhar com modelos matemáticos, os quais não englobam todas as variáveis, foi detectado que, em condições ideais, esta resistência não seria suficiente, podendo danificar o LED ou encurtar sua vida útil. Por meio da simulação no software Tinkercad este fato foi corroborado. Consequentemente, o robô foi ajustado para possibilitar a construção de atividades na SD.

Portanto, foi montado um seguidor de linha, com peças compradas, com base em experiências de outros autores. Posteriormente, foram feitos dois experimentos com componentes de sucata, com foco em estabelecer atividades que explorassem a Matemática e Física, para composição de uma SD. Na próxima seção, estão descritas as atividades elaboradas a partir da vivência das experiências aqui relatadas.

\section{Aprendizagens possíveis durante a construção da estrutura do AGV}

A Robótica Educacional é uma ferramenta que possibilita resolver problemas matemáticos e interdisciplinares com a utilização de hardware e software, evidenciando a aplicabilidade da Matemática e da Física. Vale ressaltar que nesta abordagem, assume-se a perspectiva de que educar é muito mais do que treinar pessoas para o uso das novas tecnologias, "trata-se de formar os indivíduos para aprender a aprender de modo a serem capazes de lidar positivamente com a contínua e acelerada transformação da base tecnológica" (TAKAHASHI; CIÊNCIA E TECNOLOGIA; INFORMAÇÃO (BRAZIL), 2000, p. 45).

Esse viés de pensamento é essencial na obtenção de resultados em contrapartida dos problemas sociais gerados pelos avanços tecnológicos. Existem pesquisas que relatam os impactos da tecnologia na sociedade, por exemplo no O Globo, “UnB mostra que 30 milhões de empregos serão substituídos por robôs até 2026" (CARVALHO, 2019). Uma maneira de amenizar esses problemas é formar pessoas capazes de se adaptar rapidamente às exigências do mercado, com conhecimentos sobre software e hardware, além de adequar as metodologias para o ensino e aprendizagem de Matemática que é base essencial para a tecnologia.

A construção deste robô é uma oportunidade de abordar diversos conceitos matemáticos e físicos de forma significativa para os envolvidos, bem como instigá-los para a aprendizagem de conceitos de eletrônica e computação. Nesta seção será evidenciada a Matemática e a Física subjacentes.

O projeto é muito importante para que se construa um AGV eficiente e eficaz, pois esse modelo não tem um volante. Neste caso, as rodas com tração são fixas e o giro do corpo do robô pode ser induzido de duas formas, ou pela interrupção de um dos motores enquanto o outro permanece em movimento, ou por velocidades diferentes em cada uma das rodas. A terceira roda, ou eixo fixo, facilita as manobras. Ademais, a fim de promover a estabilidade sobre as 3 rodas é necessário que o peso esteja bem distribuído. 


\subsection{Conceitos geométricos e unidades de medida}

Inicialmente, é possível trabalhar figuras planas para a escolha do modelo do chassi. Outro conceito importante é o de centro de massa, o qual pode ser trabalhado no triângulo referência. É o centro de massa deste triângulo que será usado para colocar a bateria, o componente de maior massa do robô. Portanto, é possível trabalhar conceitos como unidades de medida de massa, triângulos, triângulos isósceles, vértices, lados, lado oposto a um vértice, unidades de medida de comprimento, ponto médio de um segmento, mediana, intersecção de semirretas e baricentro (centro de massa), dentre outros. Posteriormente, ao construir as rodas, é possível trabalhar os conceitos de círculo, circunferência, diâmetro, raio e comprimento de circunferência. No desenvolvimento dessas atividades pode-se abordar as possíveis relações, por exemplo sobre o comprimento dos segmentos de reta estabelecidos na mediana a partir da determinação do baricentro.

A partir do centro de massa inicia-se a distribuição dos componentes. Neste momento podem ser abordados os conceitos de design e aerodinâmica, reforçando a necessidade de utilização de conhecimentos científicos, em particular matemáticos, para tomar decisões na construção de tecnologias, minimizando os testes. Os testes são importantes, pois são hipóteses a serem provadas e nesse processo há aprendizagem, contudo é preciso valorizar a pesquisa na solução de um problema.

\subsection{Proporcionalidade, função linear e outros conceitos}

Outra fase que propicia a abordagem de conteúdos matemáticos é trabalhar com motores/polias/engrenagens. Pode-se explorar proporcionalidade, função linear e outros conceitos, desmontando um conjunto como o indicado na Figura 2.

É importante abordar que os motores utilizados possuem alta velocidade e pouca força. Esta característica não é muito interessante, pois a força pode não ser suficiente para movimentar o robô e com grande velocidade perde-se precisão no movimento, principalmente por não haver volante. Então, surge a primeira dificuldade, ganhar torque e reduzir as altas velocidades dos motores. O ideal é que a rotação das rodas fique abaixo de 250 RPM. A solução é utilizar um conjunto de polias/engrenagens, sendo uma polia pequena fixada no motor $\left(P_{1}\right)$, uma polia grande $\left(P_{2}\right)$ acoplada a uma engrenagem pequena $\left(E_{2}\right)$ e uma engrenagem maior $\left(E_{1}\right)$ acoplada à roda, conforme Figura 17 . Segue uma proposta de abordagem dos conteúdos.

\subsubsection{Primeira atividade}

Nessa atividade é possível trabalhar conceitos como comprimento da circunferência, raio, grandezas diretamente proporcionais, frações, números decimais, funções lineares, domínio e imagem de uma função linear, inversa de uma função linear, além das operações básicas. O objetivo é encontrar uma função linear para determinar o número de voltas da $P_{2}$ em relação ao número de voltas da $P_{1} \mathrm{e}$ vice-versa.

1. Recorde/Introduza a definição e a fórmula para calcular o comprimento da circunferência $(C=$ $2 \pi R)$.

2. Utilize para demonstração as polias e engrenagens ilustradas na Figura 17.

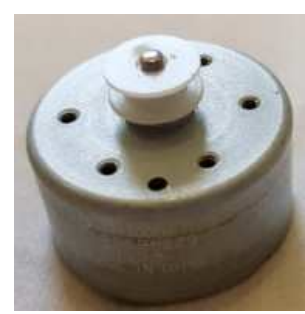

(a) Motor $/ P_{1}$.

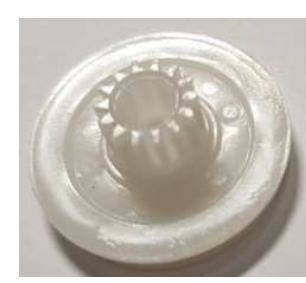

(b) $P_{2} / E_{2}$.

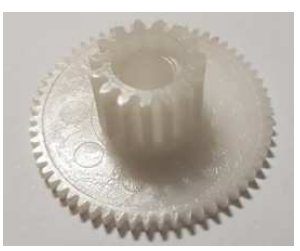

(c) $E_{1}$ e engrenagem onde será conectada a roda.

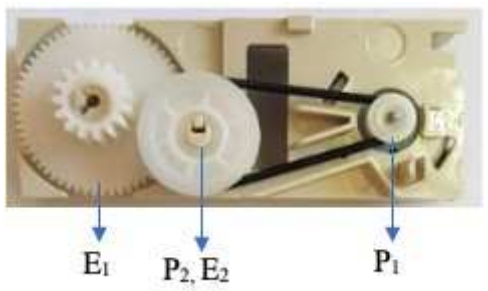

(d) $P_{1}$ e $P_{2}$ conectadas por correia $E_{1}$ e $E_{2}$ em contato.

Figura 17. Polias e engrenagens.

Fonte: Acervo dos autores.

2.1 Calcule o raio de $P_{1}(0,27 \mathrm{~cm})$ e seu comprimento $(\approx 1,69 \mathrm{~cm})$. 
2.2 Calcule o raio de $P_{2}(0,9 \mathrm{~cm})$ e seu comprimento $(\approx 5,65 \mathrm{~cm})$.

2.3 Relembre/introduza o que são grandezas diretamente proporcionais utilizando como exemplo o raio e o comprimento da circunferência.

2.4 Induza os estudantes a perceberem que uma volta completa da $P_{2}$ (maior) implica 3,343 rotações da $P_{1}$, ou equivalentemente, cada rotação da $P_{1}$ implica que $P_{2}$ gira a fração $1,69 / 5,65$ $(\approx 0,299)$.

3. Recorde/introduza a definição de função linear, domínio e imagem. Defina uma função para determinar o número de voltas da $P_{2}$ em relação ao número de voltas da $P_{1}$ e outra para determinar o número de voltas da $P_{1}$ em relação ao número de voltas da $P_{2}$.

$$
\begin{array}{rr}
f_{1}: \mathbb{R}^{+} \rightarrow \mathbb{R}^{+} & f_{1}^{-1}: \mathbb{R}^{+} \rightarrow \mathbb{R}^{+} \\
x \rightarrow 0,299 x & x \rightarrow 3,343 x
\end{array}
$$

\subsubsection{Segunda atividade}

Nessa atividade é possível trabalhar funções lineares, domínio e imagem de funções lineares, inversa de uma função linear, frações, números decimais e operações básicas. O objetivo é encontrar uma função linear para determinar o número de voltas da $E_{1}$ com relação ao número de voltas da $P_{2}$ e vice-versa.

1. Chame a atenção para o fato de que a $P_{2}$ está acoplada a uma engrenagem de 14 dentes (Figura $17 \mathrm{~b}$ ) e estão centradas no mesmo eixo. Como consequência, a cada giro da $P_{2}$ corresponde um giro da $E_{2}$

2. Enfatize que o giro de $E_{2}$ movimenta uma engrenagem de 60 dentes ( $E_{1}$ - Figura 17c), pois as duas estão em contato, conforme Figura 17 d. Nessa Figura não é possível ver a $E_{2}$, acoplada à $P_{2}$. É importante relembrar que a $E_{1}$ será presa à roda.

3. Induza os estudantes a concluírem que para $E_{1}$ dar um giro completo a $P_{2}$ precisa girar $60 / 14(\approx$ $4,285)$ voltas, ou a cada volta da $P_{2}$ a $E_{1}$ gira a fração $14 / 60(\approx 0,233)$.

4. Recorde/introduza a definição de função linear, domínio, imagem. Introduza uma função para determinar o número de voltas da $E_{1}$ com relação ao número de voltas da $P_{2}$ e outra para determinar o número de voltas da $P_{2}$ com relação ao número de voltas da $E_{1}$.

$$
\begin{array}{rlrl}
f_{2}: \mathbb{R}^{+} & \rightarrow \mathbb{R}^{+} & f_{2}^{-1}: \mathbb{R}^{+} & \rightarrow \mathbb{R}^{+} \\
x & \rightarrow 0,233 x & x & \rightarrow 4,285 x
\end{array}
$$

\subsubsection{Terceira atividade}

Nesta atividade é possível trabalhar composição de funções lineares, domínio e imagem de uma função composta, comprimento de uma circunferência, conversão de unidades de velocidade e operações básicas. O objetivo é calcular a velocidade que o AGV vai atingir.

1. Faça um apanhado sobre composição de funções e introduza a função $f_{2} \circ f_{1}$

$$
\begin{aligned}
f_{2} \circ f_{1}: \mathbb{R}^{+} & \rightarrow \mathbb{R}^{+} \\
x & \rightarrow 0,0696 x
\end{aligned}
$$

2. Induza os estudantes a concluírem que, a partir da composição das funções $f_{1}$ e $f_{2}$, é possível relacionar a quantidade de giros da roda (giros da $E_{1}$ ) com o número de voltas do motor (giros da $P_{1}$ ) e determinar o número de rotações por minuto (RPM) da roda com respeito ao número de RPM do motor.

3. Solicite que os estudantes calculem o número de RPM da roda, indicando que o motor gira 3520 RPM com atrito (veja datasheet ${ }^{7}$ ). O professor precisa ficar atento a numeração dos motores e das respectivas informações nos datasheet. Verifique se todos concluíram que o número de rotações

7 Disponível em: https://datasheetspdf.com/parts/RF-300EA-1D390.pdf?id=917203. 
da roda é, aproximadamente, 245 RPM.

4. Relembre/introduza como calcular o comprimento de uma circunferência e solicite que calculem o comprimento das rodas $(\approx 15,7 \mathrm{~cm})$, tendo em vista que o raio delas é $2,5 \mathrm{~cm}$.

5. Induza à conclusão de que o AGV percorrerá $3846 \mathrm{~cm} / \mathrm{min}$, ou $64,1 \mathrm{~cm} / \mathrm{s}$.

Infelizmente, na prática há vários outros fatores, como peso do robô, frenagens dos motores para a correção da trajetória, oscilação da tensão nos motores, capacidade elétrica da fonte de alimentação, entre outros, que interferem na quantidade de RPM da roda, como será visto no Item 6 da Seção 4.2.4.

\subsubsection{Quarta atividade}

Nesta atividade é possível trabalhar cálculo de velocidade, conversão de unidades de medida e unidades de velocidade, comprimento da circunferência, função inversa, números decimais e operações básicas. O objetivo é calcular o número médio de RPM do motor a partir da distância percorrida pelo AGV. Vale ressaltar que os valores obtidos, pelos pesquisadores, empiricamente com o robô é uma média feita a partir das testagens. Além disso, estão citados no trabalho (entre parênteses) apenas para referência, pois outros robôs, provavelmente, terão desempenhos diferentes, assim como aconteceu com os dois exemplares citados no artigo.

1. Faça os estudantes construírem uma pista, usando fita isolante preta (dupla $3,5 \mathrm{~cm}$ de largura) sobre um piso claro ou duas cartolinas chambril, conforme Figura 18. O fundo branco facilita a identificação, pelos sensores, da diferença de cores e aumenta a eficiência do AGV para seguir a linha, gerando ganhos na velocidade.

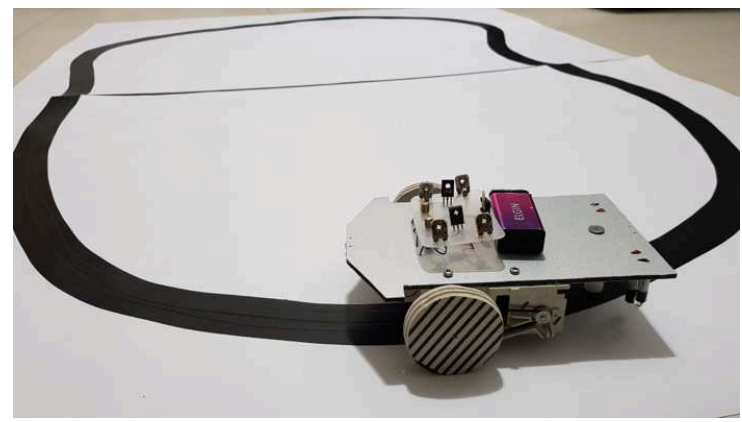

Figura 18. Pista com fita dupla de $3.21 \mathrm{~m}$.

Fonte: Acervo dos autores.

2. Solicite que determinem, empiricamente, o comprimento da trajetória em metros e centímetros $(3,21 \mathrm{~m}$ ou $321 \mathrm{~cm})$.

3. Requisite que cada estudante/grupo teste seu robô e determine o tempo gasto para percorrer o trajeto $(6,42 \mathrm{~s})$.

4. Fale sobre velocidade média e induza-os a concluir qual é a velocidade média do $A G V \mathrm{em} \mathrm{cm} / \mathrm{ms}$, $\mathrm{m} / \mathrm{s}$ e $\mathrm{cm} / \mathrm{min}(0,0005 \mathrm{~m} / \mathrm{ms}, 0,5 \mathrm{~m} / \mathrm{s}, 3000 \mathrm{~cm} / \mathrm{min})$.

5. Relembre qual o comprimento da circunferência da roda $(15,7 \mathrm{~cm})$ e solicite que calculem quantos giros da roda serão necessários para percorrer o trajeto (321cm e 20,44 giros).

6. Relembre a velocidade média do robô em $\mathrm{cm} / \mathrm{min}$ e faça-os calcular quantas RPM a roda fará

$$
\frac{3000}{15,7} \approx 191 \mathrm{RPM}
$$

Enfatize que esse foi o número de RPM da roda no teste.

7. Retome o item 3) da Seção 4.2.3 (245 RPM da roda). Ressalte a grande perda de giro e levante as possíveis causas relatadas na mesma seção.

8. Faça uma abordagem sobre função inversa e coloque como desafio que os estudantes calculem o número médio de RPM do motor a partir da distância percorrida pelo $A G V$ e do número de rotações da roda (191 RPM). Para resolver o desafio deverão utilizar a função inversa de $f_{2} \circ f_{1}$ (aplicada a 191 RPM, obtendo 2744 RPM). 


\subsection{Quinta atividade}

Nessa atividade é possível trabalhar torque, potência, proporcionalidade, interpretação de dados e operações básicas. O objetivo é calcular o ganho de torque na roda $\left(E_{1}\right)$ com respeito à $P_{1}$ e da $P_{2}$ com respeito ao motor $\left(P_{1}\right)$.

1. Instigue os alunos sobre porque utilizar engrenagens/polias, Figura $17 \mathrm{~d}$, ao invés de ligar as rodas diretamente aos motores. A mediação da discussão deve ser feita de forma a concluir que, com o uso de engrenagens/polias, ganha-se potência/força para movimentar o AGV.

2. Relembre que para $E_{1}$ dar um giro completo a $P_{2}$ precisa girar 4,285 voltas e conclua que

$$
2 \pi R_{E 1}=4,285\left(2 \pi R_{P 2}\right) \Rightarrow R_{E 1}=4,285 R_{P 2}
$$

3. Fale sobre velocidade angular ( $\omega$ - grandeza que mede a rapidez com que é feito um percurso em sentido circular), velocidade tangencial ( $V=R \omega$, onde $R$ é o raio da polia) e que em polias/engrenagens acopladas por correia as velocidades tangenciais são iguais.

$$
V_{P 2}=V_{E 1} \Leftrightarrow R_{P 2} \omega_{P 2}=R_{E 1} \omega_{E 1} \Leftrightarrow R_{P 2} \omega_{P 2}=4,285 R_{P 2} \omega_{E 1} \Leftrightarrow \frac{\omega_{P 2}}{\omega_{E_{1}}}=4,285
$$

4. Fale sobre torque, introduzindo a equação $P=T \omega(P$ - potência, $T$ - torque e $\omega$ - velocidade angular).

5. Explique que na transmissão da potência entre engrenagens há uma perda no deslizamento entre os dentes, que pode ser desconsiderada.

6. Assumindo a potência igual para $P_{2}$ e $E_{1}$, conclua que houve um ganho de 4,285 de torque na $E_{1}$ com respeito ao torque da $P_{2}$.

$$
P_{E_{1}}=P_{P_{2}} \Leftrightarrow T_{E_{1}}=\frac{\omega_{P_{2}}}{\omega_{E_{1}}} T_{P_{2}} \Leftrightarrow T_{E_{1}}=4,285 T_{P_{2}}
$$

7. Realizando o mesmo estudo para $P_{1}$ e $P_{2}$, onde cada volta da $P_{2}$ corresponde a 3,343 voltas da $P_{1}$, conclua que houve um ganho de 14,32 de torque na roda $\left(E_{1}\right)$ em relação ao torque do motor $\left(P_{1}\right)$, conseguindo gerar força para deslocar o AGV no percurso.

$$
T_{P_{2}}=\frac{\omega_{P_{1}}}{\omega_{P_{2}}} T_{P_{1}} \Rightarrow T_{P_{2}}=3,343 T_{P_{1}} \Rightarrow T_{P_{1}} \Rightarrow T_{E_{1}}=4,285 T_{P_{2}}=14,32 T_{P_{1}}
$$

Observação: Pode ser uma boa estratégia solicitar que sejam construídos robôs com rodas de tamanhos diferentes para que possam investigar qual é a melhor opção, para mais detalhes veja a Seção 6 .

\section{Abordagens matemáticas possíveis a partir do estudo da parte eletrônica do AGV}

Se for objetivo do professor aprofundar no estudo sobre o funcionamento do AGV, seguem algumas atividades básicas. Estas atividades pressupõem o conhecimento de alguns conceitos básicos de circuitos eletrônicos que não serão tratados neste trabalho. Por exemplo, circuito eletrônico de corrente contínua, corrente elétrica (unidade de medida Amperes (A) e é representada por I), fonte de alimentação, potência (unidade de medida Watt $(W)$ e é representada por $P$ ), resistência elétrica (unidade de medida $\Omega(\mathrm{Ohm})$ e é representada por $R$ ), tensão elétrica (unidade de medida Volt $(\mathrm{V})$ e é representada por $V$ ) e lei de $\mathrm{Ohm}(V=I R)$. A seguir serão abordados alguns conceitos e resultados sobre circuitos associados em série e em paralelo.

\subsection{Circuitos associados em série}

Nessa atividade é possível trabalhar coleta de dados em esquemas, equações, operações básicas, notação e significado de somatório. O objetivo é introduzir algumas noções básicas sobre circuitos associados em série.

1. Introduza os circuitos associados em série, iniciando a representação por meio de esquemas. $\mathrm{Na}$ 
Figura 19 é possível visualizar um esquema de um circuito com 4 resistores em série. Ressalte que podem ser colocados quaisquer componentes eletrônicos no circuito.

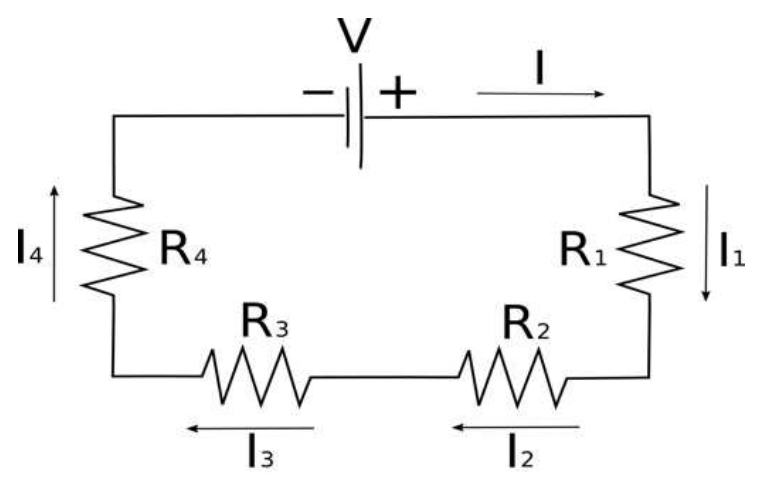

Figura 19. Circuito associado em série.

Fonte: Acervo dos autores.

2. Discuta a $2^{a}$ Lei de Kirchhoff (Lei das Malhas e suas consequências), segundo a qual a soma algébrica das diferenças de potencial (ou tensão) de uma malha é igual a zero e a corrente é igualmente distribuída em todos os componentes no circuito.

3. Ilustre a referida lei a partir da Figura 19 , concluindo que $V=V_{1}+V_{2}+V_{3}+V_{4}$, onde $V_{i}$ é a tensão no resistor $R_{i}$, para $i=1,2,3,4$.

4. Deduza que $I=I_{1}=I_{2}=I_{3}=I_{4}$, com $I_{i}$ a corrente elétrica no resistor $R_{i}$, para $i=1,2,3,4$.

5. Argumente que, pela Lei de Ohm,

$$
R I=V=\sum_{i=1}^{4} V_{i}=\sum_{i=1}^{4} R_{i} I_{i}=\sum_{i=1}^{4} R_{i} I=I \sum_{i=1}^{4} R_{i} \Rightarrow R=\sum_{i=1}^{4} R_{i}
$$

6. Generalize a fórmula para o caso $\mathrm{n}$.

\subsection{Circuitos associados em paralelo}

Nessa atividade é possível trabalhar coleta de dados em esquemas, equações, operações básicas, notação e significado de somatório. O objetivo é introduzir algumas noções básicas sobre circuitos associados em paralelo.

1. Introduza os circuitos associados em paralelo. Utilize, como exemplo, o esquema da Figura 20 de um circuito de 4 resistores em paralelo. Ressalte que podem ser colocados quaisquer componentes eletrônicos no circuito que continuarão valendo as conclusões.

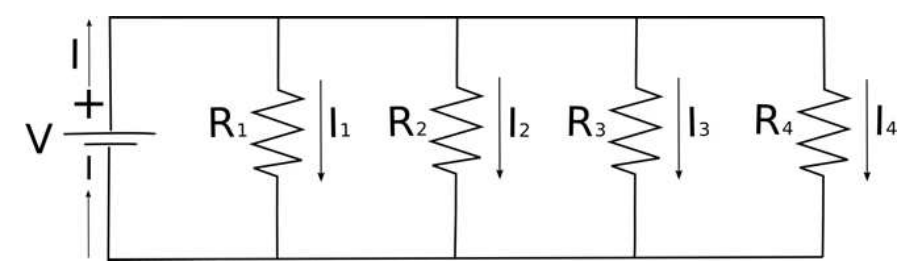

Figura 20. Circuito associado em paralelo.

Fonte: Acervo dos autores.

2. Discuta a $1^{a}$ Lei de Kirchhoff (Lei dos Nós), segundo a qual, em qualquer nó, a soma das correntes que o deixam é igual à soma das correntes que chegam até ele.

3. Ilustre a referida lei a partir da Figura 20, onde $I=I_{1}+I_{2}+I_{3}+I_{4}$.

4. Conclua que, $V=V_{1}=V_{2}=V_{3}=V_{4}$, pois estão conectados aos mesmos pontos. 
5. Deduza, pela Lei de Ohm, que

$$
\frac{V}{R}=I=\sum_{i=1}^{4} I_{i}=\sum_{i=1}^{4} \frac{V_{i}}{R_{i}}=\sum_{i=1}^{4} \frac{V}{R_{i}}=V \sum_{i=1}^{4} \frac{1}{R_{i}} \Rightarrow \frac{1}{R}=\sum_{i=1}^{4} \frac{1}{R_{i}}
$$

6. Generalize a fórmula para o caso $n$.

\subsection{Escolha do resistor}

Nessa atividade é possível trabalhar coleta de dados em esquemas, equações, função linear, função exponencial e operações básicas. O objetivo nessa seção é calcular a resistência máxima do resistor para não queimar o LED.

1. Esquematize o primeiro circuito, LED-resistor, conforme Figura 21, ressaltando a simbologia utilizada

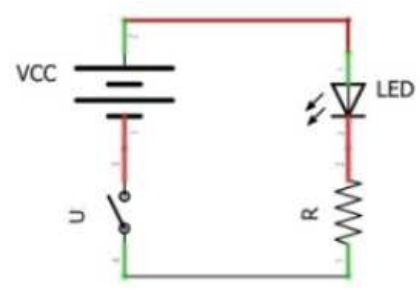

Figura 21. Esquema do primeiro circuito.

Fonte: Acervo dos autores.

2. Instigue os estudantes com a pergunta: sabendo a tensão na fonte (9V) e a tensão do LED (3V), como escolher qual resistor utilizar de forma a evitar a queima do LED? Relembre que a corrente no LED é de 0,02A.

3. Argumente que, por ser um circuito associado em série

$$
V_{F A}=V_{L E D}+V_{R} \quad \text { e } \quad l=I_{L E D}=I_{R}
$$

em que, $V_{F A}$ - tensão na fonte, $V_{L E D}$ e $I_{L E D}$ - tensão e corrente no LED e $V_{R}$ e $I_{R}$ - tensão e corrente no resistor.

4. Conclua, pela Lei de Ohm, que a resistência no resistor será

$$
R_{R}=\frac{V_{R}}{I_{R}}=\frac{V_{F A}-V_{L E D}}{l_{L E D}}=\frac{9-3}{0,02}=300
$$

5. Esclareça que resistores de $300 \Omega$ não são comuns e que, neste caso, será utilizado um resistor de $220 \Omega$ e um de $100 \Omega$ colocados em série, os quais evitarão a queima do LED por ter uma resistência pouco maior do que a calculada.

6. Explique que a resistência dos resistores é registrada por um código de cores, conforme Figura 22, onde as primeiras três faixas indicam o valor nominal e a última, a porcentagem que a resistência pode variar.

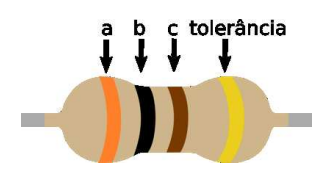

Figura 22. Resistor de 4 cores.

Fonte: Acervo dos autores.

7. Exponha que a função para encontrar o valor nominal do resistor de 4 cores é

$$
R(a, b, c)=(10 a+b) 10^{c}
$$


E conclua quais cores devem ter as faixas, conforme Tabela $3\left(300 \Omega=R(3,0,1)=(10 \times 3+0) 10^{1}\right.$, ou seja, laranja, preto, marrom, o de $220 \Omega$ vermelho, vermelho, marrom e o de $100 \Omega$ marrom, preto, marrom). É uma oportunidade para abordar função exponencial.

Tabela 3. Tabela de cores: Valor nominal.

\begin{tabular}{llllllllllll}
\hline \multicolumn{1}{l}{ Valor nominal } & \multicolumn{10}{l}{} \\
\hline Cor & Preto & Marrom & Vermelho & Laranja & Amarelo & Verde & Azul & Violeta & Cinza & Branco \\
\hline Valor & 0 & 1 & 2 & 3 & 4 & 5 & 6 & 7 & 8 & 9 \\
\hline
\end{tabular}

Fonte: Acervo dos autores.

\subsection{Atividade final}

Conhecendo o transistor, seu ganho beta (informado no datasheet), bem como o motor e sua faixa de funcionamento (informado no datasheet), é possível delimitar as resistências para o LDR e o potenciômetro que propiciam o funcionamento dos motores. Além disso, medindo a resistência do LDR com um multímetro, na pista proposta, pode-se delimitar faixas de resistência do potenciômetro para o funcionamento dos motores. Nesta perspectiva, pode-se confeccionar o circuito sem testes, bem como substituir os potenciômetros no circuito LDR-potenciômetro por resistores.

Como o objetivo deste artigo é propor atividades não muito complexas onde seja possível evidenciar a Matemática subjacente, será proposta como atividade final o cálculo da tensão no ponto de nó (teoria de divisão de tensão ${ }^{8}$ ), que no caso em tela é a tensão no potenciômetro Vpot.

Nessa atividade é possível trabalhar coleta de dados em esquemas, equações, sistema de equações lineares, funções e operações básicas. O objetivo é calcular a tensão no ponto de nó LDRpotenciômetro-transistor, Figura 23, buscando determinar uma equação que relacione a tensão/corrente que vai para o transistor com a tensão de entrada.

1. Esquematize o circuito, conforme Figura 23. Explique onde está o ponto de nó e qual o objetivo.

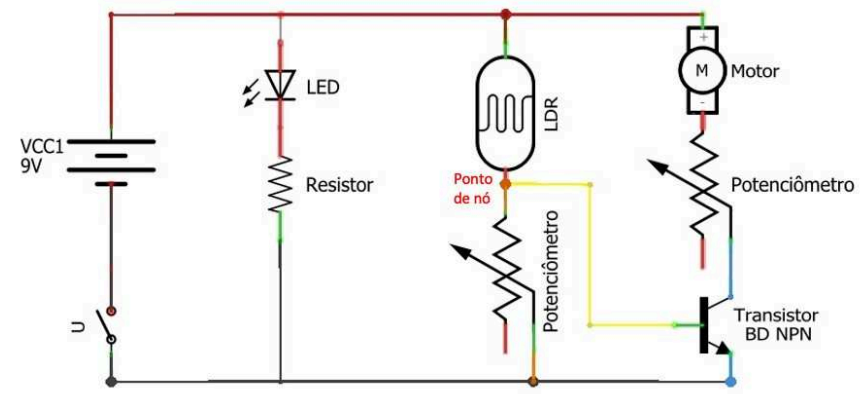

Figura 23. Esquema do circuito do AGV.

Fonte: Acervo dos autores.

2. Esquematize o segundo circuito, Figura 24. Ressalte que a tensão já passou pela primeira resistência (LDR) e agora só depende da tensão que chega à segunda (potenciômetro). A tensão no ponto de nó é igual à tensão do potenciômetro.

3. Comente que o circuito LDR-potenciômetro está em série, Figura 24, e por isso tem-se

$$
I_{L D R}=I_{\text {pot }}, \quad V=V_{L D R}+V_{\text {pot }} \quad \text { e } \quad R=R_{L D R}+R_{\text {pot }}
$$

4. Utilize a lei de Ohm, para obter um sistema de equações lineares

$$
\left\{\begin{array}{l}
V_{F A}=I R=I\left(R_{L D R}+R_{p o t}\right) \\
V_{p o t}=I R_{p o t}
\end{array} \Rightarrow V_{p o t}=\frac{R_{p o t}}{R_{L D R}+R_{p o t}} V_{F A}\right.
$$

8 Para saber mais: https://pt.khanacademy.org/science/electrical-engineering/ee-circuit-analysis-topic/ee-resistor-circu its/a/ee-voltage-divider. Acesso em 02 de agosto de 2020. 


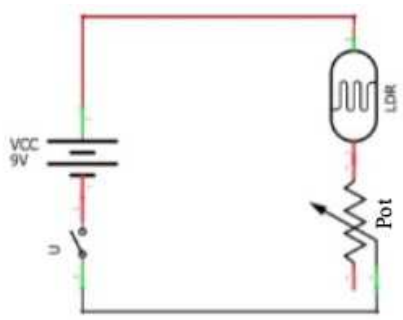

Figura 24. Esquema do segundo circuito do AGV.

Fonte: Acervo dos autores.

Assim, é possível calcular a tensão no potenciômetro em função da tensão de entrada e das resistências do potenciômetro e do LDR, sem conhecer a corrente do potenciômetro. Para aplicar ao AGV construído, relembre que a fonte de alimentação é de $9 \mathrm{~V}$ e suponha que a resistência do potenciômetro deve ser ajustada a $220 \Omega$.

5. Substituindo os valores na fórmula, obtenha a tensão no potenciômetro em função da resistência do LDR

$$
V_{\text {pot }}=\frac{220}{R_{L D R}+220} 9 .
$$

6. Explique o resultado anterior abordando conceitos relativos a funções.

Agora é possível aplicar as relações obtidas nessa seção para a pista e AGV construídos. É importante relembrar que a base da pista é clara e a trajetória foi feita com uma fita isolante de cor preta (dupla) de $3,5 \mathrm{~cm}$ de largura.

7. Inicie a abordagem dividindo o estudo em três casos com respeito ao posicionamento do LDR sobre a trajetória, conforme a Figura 25.
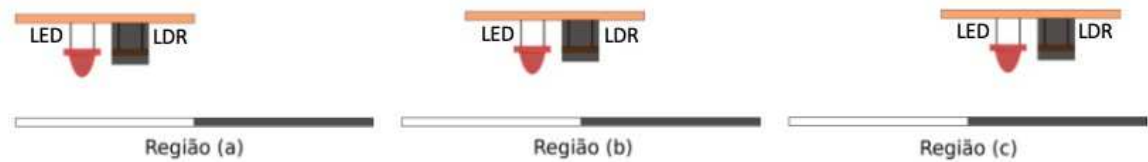

Figura 25. Posicionamento do LDR sobre a trajetória.

Fonte: Acervo dos autores.

8. Solicite que os estudantes façam a leitura das resistências dos LDR conforme regiões definidas na Figura 25 com um multímetro ${ }^{9}$.

9. Faça com que os estudantes calculem o $V_{\text {pot }}$, para $R_{\text {pot }}=220 \Omega$ (faixa do transistor NPN BD) e para $R_{\text {pot }}=470 \Omega$ (faixa do transistor NPN TIP). Para direcionamento, considerando altura do LDR do chão igual a $1 \mathrm{~cm}$, a iluminação com um LED de $3 \mathrm{~V}$ a uma altura de $1 \mathrm{~cm}$ do chão e distante $1 \mathrm{~cm}$ do LDR e $V_{F A}=9 \mathrm{~V}$, serão obtidos os valores da Tabela 4:

Tabela 4. Aferição de resistências e tensões nas regiões.

\begin{tabular}{llll}
\hline Local & $R_{L D R}$ & $V_{\text {pot }}$ para $R_{\text {pot }}=220 \Omega$ & $V_{\text {pot }}$ para $R_{\text {pot }}=470 \Omega$ \\
\hline Região (a) & $1120 \Omega$ & $1,47 \mathrm{~V}$ & $2,66 \mathrm{~V}$ \\
Região (b) & $1380 \Omega$ & $1,23 \mathrm{~V}$ & $2,28 \mathrm{~V}$ \\
Região (c) & $2500 \Omega$ & $0,72 \mathrm{~V}$ & $1,42 \mathrm{~V}$ \\
\hline
\end{tabular}

Fonte: Acervo dos autores.

Assim, conclui-se a exposição de diversas atividades que evidenciam a Matemática e a Física, as quais podem ser executadas durante a construção do AGV. Espera-se que os leitores busquem outras abordagens e compartilhem suas experiências.

9 Veja em: https://www.youtube.com/watch?v=XW2ZBwCD9dl. 


\section{Uma Experiência com diferentes AGV}

Este trabalho foi elaborado tendo como base o AGV retratado nas Figuras 14 e 16 . Um exemplar, Figura 26, foi construído, anteriormente, com alguns componentes diferentes.

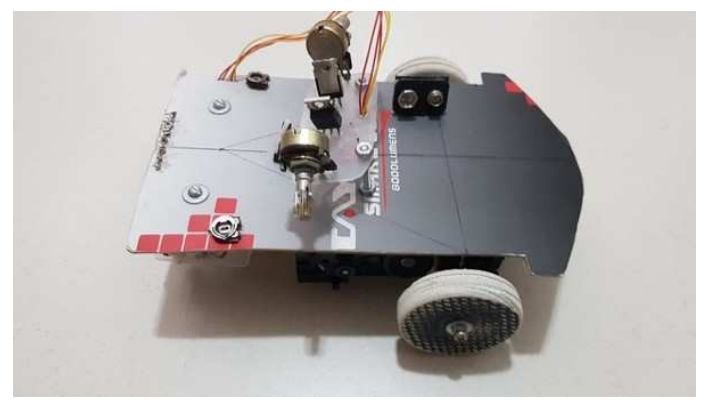

(a)

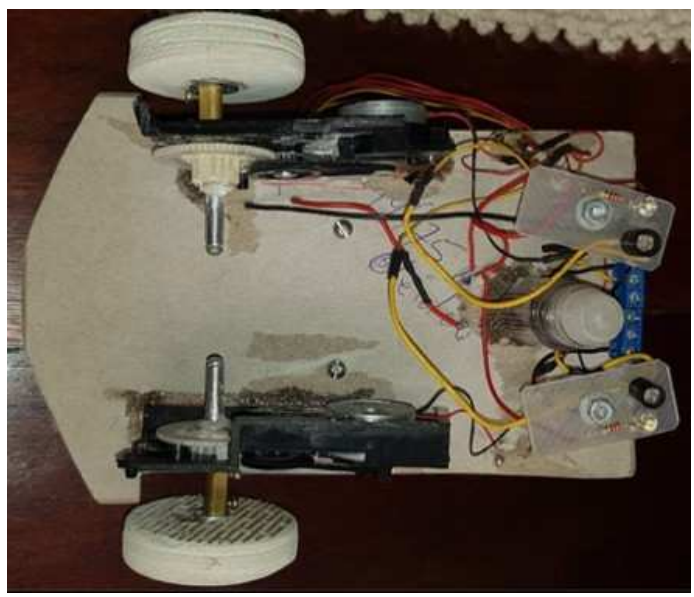

(b)

Figura 26. Primeiro exemplar (AGV).

Fonte: Acervo dos autores.

Com o objetivo de estimular diferentes experiências, nessa seção são relatadas as diferenças na construção dos exemplares e qual foi o impacto na velocidade e precisão deles.

Tabela 5. Componentes do primeiro e segundo exemplares do AGV.

\begin{tabular}{|c|c|}
\hline AGV segundo Exemplar & AGV primeiro Exemplar \\
\hline \multicolumn{2}{|c|}{ Roda dianteira de roll-on labial } \\
\hline \multicolumn{2}{|c|}{ Roda traseira de chinelo } \\
\hline \multicolumn{2}{|c|}{ Placa para fixar componentes de pasta de plástico } \\
\hline \multicolumn{2}{|c|}{1 resistor de $220 \Omega$ e 1 resistor de $100 \Omega$ (em série) } \\
\hline \multicolumn{2}{|c|}{ LED de alto brilho de luminária de Emergência de 3V } \\
\hline \multicolumn{2}{|c|}{ LDR $5 \mathrm{~mm}$} \\
\hline \multicolumn{2}{|c|}{ Chave (liga/desliga) } \\
\hline \multicolumn{2}{|c|}{ Clip conector de bateria $9 v$} \\
\hline Chassi de ACM & Chassi de capa rígida de caderno \\
\hline Transistor NPN BD135 & Transistor PNP TIP 105 \\
\hline $\begin{array}{l}\text { Motores de leitora de DVD de computador, } \\
\text { de } 3520 \text { RPM, com engrenagens ( } 60 \text { e } 14 \\
\text { dentes) e polias }\end{array}$ & $\begin{array}{l}\text { Motores de aparelho de DVD, de } \\
\text { 3520RPM,com engrenagens ( } 64 \text { e } 14 \text { dentes) } \\
\text { e polias }\end{array}$ \\
\hline $\begin{array}{l}2 \text { Potenciômetros trimpot } 500 \Omega \text { para regular } \\
\text { as velocidades dos motores }\end{array}$ & $\begin{array}{l}2 \text { Potenciômetro trimpot } 2 K \Omega \text { para regular } \\
\text { as velocidades dos motores }\end{array}$ \\
\hline $\begin{array}{l}2 \text { Potenciômetros trimpot } 5 K \Omega(120 \Omega \text { à } \\
330 \Omega) \text { para regular as correntes para as bases } \\
\text { dos transistores }\end{array}$ & $\begin{array}{l}2 \text { Potenciômetros } 10 K \Omega(200 \Omega \text { à } 600 \Omega) \\
\text { para regular as correntes para as bases dos } \\
\text { transistores }\end{array}$ \\
\hline
\end{tabular}

Fonte: Acervo dos autores.

A mesma análise em relação ao número de RPM da roda versus o número de RPM do motor pode ser realizada para o primeiro AGV. Como a única alteração determinante ocorreu na engrenagem $E 1$ (64 dentes e 60 dentes), a função definida no Item 1 da Seção 4.2.3 para o primeiro AGV é

$$
\begin{aligned}
h: \mathbb{R}^{+} & \rightarrow \mathbb{R}^{+} \\
x & \rightarrow 0,0654 x
\end{aligned}
$$


Como o número de rotações do motor é o mesmo para ambos os robôs, 3520 RPM, tem-se 230 RPM para as rodas do primeiro AGV. Nos testes realizados no percurso, o primeiro AGV percorreu a pista de $3,21 \mathrm{~m}$ em $6,73 \mathrm{~s}$, ou seja, com velocidade média de $0,476 \mathrm{~m} / \mathrm{s}$ ou $2.861 \mathrm{~cm} / \mathrm{min}$. Na prática, como a roda do primeiro AGV possui $2,37 \mathrm{~cm}$ e seu comprimento de arco é $14,9 \mathrm{~cm}$, considerando as perdas ocorridas no percurso, obtém-se, aproximadamente, 192RPM para a roda. A Tabela 6 é um comparativo entre os dois AGV, cujos valores (exceto raio e peso) foram obtidos pela média feita a partir de vários testes.

Tabela 6. Quadro comparativo.

\begin{tabular}{lll}
\hline & Segundo AGV & Primeiro AGV \\
\hline Raio da roda traseira & $2,5 \mathrm{~cm}$ & $2,37 \mathrm{~cm}$ \\
Comprimento de arco da roda & $15,7 \mathrm{~cm}$ & $14,9 \mathrm{~cm}$ \\
Rotação da roda (matematicamente) & $245 \mathrm{RPM}$ & $230 \mathrm{RPM}$ \\
Velocidade roda & $3.846 \mathrm{~cm} / \mathrm{min}$ & $3.427 \mathrm{~cm} / \mathrm{min}$ \\
Velocidade média no percurso & $3.000 \mathrm{~cm} / \mathrm{min}$ & $2.861 \mathrm{~cm} / \mathrm{min}$ \\
Média de rotações da roda (empiricamente) & $191 \mathrm{RPM}$ & $192 \mathrm{RPM}$ \\
Peso & $230 \mathrm{~g}$ & $217 \mathrm{~g}$ \\
\hline
\end{tabular}

Fonte: Acervo dos autores.

É importante salientar que a perda de RPM no percurso foi maior para o transistor BD135 (de 245 para 191) em comparação com o transistor TIP 105 (230 para 192). Portanto, o TIP105 teve uma resposta melhor na correção do AGV. Além disso, o tamanho da roda influenciou na velocidade do robô, pois mesmo com um número menor de rotações da roda (191RPM), o segundo AGV obteve velocidade maior que o primeiro (192RPM para roda).

Portanto, as escolhas dos componentes e circuitos podem induzir a construção de um AGV mais rápido ou mais lento, mais preciso ou não. Assim, a proposta de uma competição pode ser interessante, dependendo do contexto em que estiver sendo feita esta abordagem. Porém, ressalta-se a importância da valorização não somente do robô mais preciso e veloz nessa competição, mas de todos os participantes que discutirem e apresentarem propostas, enfatizando o aprendizado e conhecimento construídos. O mais importante é incentivar a colaboração.

\section{Considerações finais}

O desenvolvimento de um projeto com RE dessa magnitude é um caminhar ao desconhecido, pois toda ação implica em uma nova descoberta, a qual proporciona um aprendizado. Desta forma, a execução do projeto é similar a um processo de resolução de problemas. E até mesmo após a finalização do projeto continuam surgindo questões, pois há sempre o desejo de melhorar a criação. Nesta busca pela perfeição, a Matemática torna-se aliada no processo de interpretação dos resultados obtidos pelo robô, orientando desde o design até a escolha dos objetos para construí-lo.

No contexto atual, de produção e consumo tecnológico, estamos produzindo muito lixo eletrônico. Logo, o trabalho com robótica utilizando sucata constitui-se uma oportunidade de aprendizagem interdisciplinar, abordando questões ambientais. Reaproveitar eletrônicos para construção de robôs abre um leque de possibilidades educativas, com o desenvolvimento de uma consciência quanto ao consumo e ao meio ambiente, podendo ser construídas propostas envolvendo diversos temas transversais no ensino.

Ensinar Matemática de forma que seja compreendida e não venha causar uma fobia é um desafio no processo de educação Matemática. As tecnologias digitais possibilitam um trabalho com conteúdos da disciplina que atrai os estudantes, pois elas já fazem parte da cultura digital de crianças e jovens. Construir um robô é um trabalho divertido e quando aliamos à Matemática estamos agregando maior conhecimento e domínio sobre a tecnologia. O que buscamos é "que os jovens de hoje, consumidores de tecnologias, possam ser mais: mais produtores, mais críticos, mais criativos, mais preocupados com os problemas locais, regionais e até globais" (BARBOSA, 2016, p. 286). 
Com RE usando de materiais livres fomenta-se uma robótica mais inclusiva e acessível, tendo em vista que materiais comercializados para fins educacionais têm um valor muito além das condições de muitas instituições de ensino públicas. Isto posto, neste artigo aborda-se uma visão de estudos de dispositivos mecânicos e eletrônicos, a partir de conceitos matemáticos, evidenciando como ela auxilia no processo de construção de um robô, utilizando sucata, e seu aperfeiçoamento. Propicia-se, assim, a elaboração de conhecimentos matemáticos em um ambiente motivador e prazeroso. Mais que ensinar Matemática, é fazer deste conhecimento fundamental e em evolução, um instrumento de transformação e leitura do mundo em que vivemos.

Em trabalhos posteriores, pretende-se aprofundar no estudo de dispositivos mecânicos e eletrônicos, a partir de conceitos matemáticos, com a finalidade de ampliar a gama de opções de mecanismos que podem ser usados para construção de robôs seguidores de linha. Além disso, objetiva-se iniciar o trabalho com microcontroladores reprogramáveis para a inserção do controle remoto no robô e introdução de programação para o público-alvo. Ademais, devem ser realizadas experimentações das atividades propostas a fim de verificar suas contribuições para a aprendizagem dos envolvidos.

\section{Referências}

BARBOSA, Fernando da Costa. Rede de Aprendizagem em Robótica: uma perspectiva educativa de trabalho com jovens. 2016. Tese (Doutorado) - Curso de Doutorado em Educação, Universidade Federal de Uberlândia, Uberlândia.

BEN, Marina de Souza Dal; SANTOS, Cristina Paludo. Tecendo espaços e experiências no campo da robótica educacional. Vivências, v. 16, n. 30, p. 173-191, 2019. Disponível em:

<http://revistas.uri.br/index.php/vivencias/issue/view/6>. Acesso em: 28 set. 2020.

BRASIL. Base Nacional Comum Curricular. Ministério da Educação e Cultura. 2018. Disponível em: $<$ http://basenacionalcomum.mec.gov.br/images/BNCC_El_EF_110518_versaofinal_site.pdf>. Acesso em: 28 set. 2020.

CAMPOS, F. R. Robótica pedagógica e inovação educacional: uma experiência no uso de novas tecnologias na sala de aula. 2005. Diss. (Mestrado) - Universidade Presbiteriana Mackenzie, São Paulo.

CARVALHO, Letícia. Pesquisa da UnB mostra que 30 milhões de empregos serão substituídospor robôs até 2026. G1, 2019. Disponível em: <https://g1.globo.com/df/distrito-federal/noticia/2019/02/03/pesquisada-unb-mostra-que-30-milhoes-de-empregos-serao-substituidos-por-robos-ate-2026.ghtml >. Acesso em: 9 ago. 2020.

LOPES, D. Q. Exploração de modelos e o nível de abstração nas construções criativas com Robótica Educacional. 2008. Tese (Doutorado) - Curso de doutorado em Informática na Educação), Universidade Federal do Rio Grande do Sul, Porto Alegre.

MILL, Daniel; CÉSAR, Danilo. Robótica pedagógica livre: sobre inclusão sócio-digital e democratização do conhecimento. Perspectiva, Florianópolis, v. 27, n. 1, p. 217-248, 2009.

PAPERT, Seymour; FREIRE, Paulo. The Future of School. [S.I.: s.n.], 1980. Disponível em: <http://www.papert.org/articles/freire/freirePart1.html>. Acesso em: 25 out. 2018.

PAZOS, Fernando. Automação de Sistemas \& Robótica. [S.I.]: Axcel Books, 2002.

SANTOS, Paulo Gabriel Franco dos. Robótica e Processos Formativos: da epistemologia aos kits. In: edição: Deise Aparecida Peralta. Porto Alegre: Editora Fi, 2019. Reflexões filosóficas em tecnologia para um pensar dialético: do encantamento à profanação, p. 15-29. Disponível em:

$<$ https://www.researchgate.net/profile/Deise_Peralta/publication/337473511_Robotica_e_Processos_ Formativos_da_epistemologia_aos_kits_Org/links/5e6690d692851c7ce05519a0/Robotica-e-ProcessosFormativos-da-epistemologia-aos-kits-Org.pdf>. Acesso em: 28 set. 2020.

SILVA, Carolina Cajazeira de Melo et al. A revolução da robótica utilizando lixo eletrônico no ensino básico: formação ampliada e menor vulnerabilidade de jovens à violência nas escolas públicas. Revista do Laboratório de Estudos da Violência da Unesp/Marília, v. 1, n. 17, p. 75-89, 2016.

TAKAHASHI, Tadao; CIÊNCIA E TECNOLOGIA, Brasil. Ministério da; INFORMAÇÃO (BRAZIL), Programa Sociedade da. Sociedade da informação no Brasil: livro verde. [S.I.]: Ministério da Ciência e Tecnologia, 2000. ISBN 9788588063013.

THENÓRIO, I. Como fazer um Robô que dirige sozinho. [S.I.: s.n.]. Disponível em: <https://www.youtube.com/watch?v=5KwH-bQYOEc>. Acesso em: 4 jul. 2020. 